\title{
A "nova" Argentina (re) vista: breves considerações acerca das representações modernas portenhas por um paulista
}

\author{
Mayra Coan Lago*
}

\section{Resumo}

Este trabalho tem como objetivo apresentar breves considerações do paulista Mário de Andrade, expressas nos quatro artigos sobre as Letras Argentinas Contemporâneas, que publicou no Diário Nacional de São Paulo entre 22 de abril e 20 de maio de 1928, sobre a “Nova" Argentina das décadas de 1920 e 1930. Mais do que expor os escritos publicados de Mário sobre o país vizinho, é preciso considerar esses momentos como de diálogo, crítica e reflexão das questões nacionais brasileiras, bem como de aproximação com a Argentina.

\section{Palavras-chave}

Modernidade. Vanguardas. Mário de Andrade.

\section{Abstract}

The objective of this work is to introduce brief considerations of the Paulista Mário de Andrade, expressed in four articles about the Contemporaneous Argentinean Letters that he published in the Diário Nacional of São Paulo between April 22nd and May 20th in 1928, about the "New" Argentina of the decades of 1920 and 1930. More than exposing Mário's writings about the neighbor country, is it important to consider these moments as moments of dialogue, critique and reflection of the Brazilian national issues, as well as of an approaching with a Latin American country.

\section{Keywords}

Modernity. Avant-gardes. Mário de Andrade.

\footnotetext{
* Mestranda no Programa de Pós-graduação Interunidades em Integração para América Latina (PROLAN) da Universidade de São Paulo (USP). E-mail: mcoann@hotmail.com .
} 


\section{Introdução}

“O movimento da revista Martín Fierro é na certa o mais vivo, mais fecundo e mais típico da literatura moderna argentina. Martín Fierro tomou e mantém cada vez mais viva uma função orientadora e selecionadora de ideias e valores caracteristicamente modernistas (...). Até o nome da revista esboça bem a força nacional. Me parece incontestável que nas suas linhas gerais a Argentina toda já vibra num ritmo psicológico único"

(ANDRADE, Diário Nacional, 13 de maio de 1928).

Sarlo (2010) considera que a história se conta com tramas compostos por cenários, sujeitos, discursos e práticas. O nosso cenário é a Argentina e, mais especificamente, a cidade de Buenos Aires. Segundo Zanetti (1994), pelo menos desde o século XIX, a cidade era notada como centro de atração do continente e centro irradiador do modernismo ${ }^{1}$. O fato justifica-se pelo dinamismo modernizador, pelas possibilidades de trabalho, pela projeção dos grandes jornais como La Nación e, ainda que incipiente, o destacado desenvolvimento da indústria editorial.

De acordo com Artundo (2004) "é evidente que Buenos Aires, com suas novas avenidas, seus parques e seus jardins operava ativamente sobre esse imaginário do moderno e continuou a fazê-lo mesmo passada a euforia competitiva entre ambas as capitais" (p. 25). Embora a cidade fosse centro irradiador para os vizinhos do Sul, alguns autores como Jorge Schwartz, Emir Monegal, entre outros, consideram que a recíproca de interesse, no caso argentino para o Brasil, salvo algumas exceções, não é "verdadeira" no início do século XX. Segundo Schwartz e Alcalá (1992), apesar da correspondência aparente, na década de 1920, os brasileiros tinham um conhecimento bem maior do que se produzia na Argentina que os argentinos em relação ao Brasil, assim como um interesse maior na busca de material e no aprofundamento da análise.

\footnotetext{
${ }^{1}$ De acordo com Sarlo (2010), o modernismo hispano-americano ocorreu no final do século XIX. O movimento representou uma superação do modelo romântico, manifestando-se especialmente na poesia, contando com nomes como os de Ruben Dário, José Marti e Leopoldo Lugones. Em linhas gerais, as características do movimento podem ser comparadas com traços do simbolismo e do parnasianismo brasileiro. Desse modo, difere bastante do modernismo paulista, cujo equivalente na América Hispânica são as vanguardas da segunda e terceira década do século XX.
} 
Schwartz (1993) e Monegal (1978) atribuíram aos escassos pontos de contato nesse período, entre outras razões, a questão do idioma². Segundo Schwartz (1993), não encontraremos até meados do século XX, qualquer intelectual hispânico que tivesse pelas letras do Brasil o interesse abrangente e sistemático que José Veríssimo, Mário de Andrade, Brito Broca e Manuel Bandeira dedicaram às literaturas do continente. Notando o fato, Monegal (1978), que sempre circulou por ambas as literaturas, afirmou: "os brasileiros cultos frequentam mais assiduamente e com maior proveito a literatura hispano-americana que seus colegas hispânicos a brasileira, devido à preguiça (ou incapacidade) de verificar se o português é tão difícil de se ler”’.

Schwartz e Alcalá (1992) utilizam-se de outra hipótese: o olhar do brasileiro frente a uma "superioridade relativa" da Argentina como país, com sua modernidade antecipada. Deste modo, na perspectiva dos autores, Buenos Aires para os paulistas poderia ser "nós amanhã". Ademais dessas hipóteses, devemos considerar o interesse de um sujeito específico, seja recíproco ou não, que representou um momento e um movimento particular no Brasil: o modernismo.

O nosso "sujeito" é o paulista Mário de Andrade: "Ávido leitor, bibliófilo incansável e copioso correspondente, Mário de Andrade sempre fez questão de manter-se informado a respeito do que se passava na literatura e nas artes dos países vizinhos, sobretudo da Argentina" (SCHWARTZ, 1993, p.189).

Com as palavras de Schwartz (1993) justificamos a escolha do intelectual e do tema. Soma-se ao fato a admiração do paulista pela Argentina, que conseguiu sintetizar na sua cultura nacional o elemento original e as heranças migratórias (SCHWARTZ; ALCALÁ, 1992) - e sua atração em fazer comparações culturais, literárias, geográficas, linguísticas entre Brasil/ Argentina e, mais especificamente, São Paulo/ Buenos Aires.

\footnotetext{
${ }^{2}$ Com relação à questão linguística, vale lembrar do artigo "Abaixo Tordesilhas!", de Schwartz (1993), em que ele menciona o clássico entrave que fez do castelhano língua mais acessível ao leitor brasileiro do que o português para o leitor hispano-americano e cita exemplos dessa situação.

${ }^{3}$ Schwartz (1993) cita como exemplo os casos de Alfonso Reyes, que foi diplomata no Brasil e aproveitou pouco sua estadia no país, quando relacionada ao intercâmbio mais próximo da literatura brasileira durante os quatro anos que dirigiu o Correo Literario de Alfonso Reyes, dedicando um espaço reduzido ao Brasil no tabloide; e Gabriela Mistral em semelhante missão, tendo o Brasil pouco influenciado em suas reflexões.
} 
Com relação aos "discursos", podemos dizer que, apesar de Mário ser considerado um "homem da biblioteca" e ter sido um leitor e um escritor assíduo, consideraremos algumas das leituras ou dos comentários feitos por ele na década de 1920 e 1930, principalmente os relacionados com as imagens, projeções e/ou representações "modernas" produzidas pelas vanguardas argentinas, por questões metodológicas. Os comentários que serão considerados são aqueles em publicações jornalísticas e, em especial, a série de quatro artigos sobre as Letras Argentinas Contemporâneas, que Mário publicou no Diário Nacional de São Paulo, entre 22 de abril e 20 de maio de 1928.

Por fim, devemos considerar as "práticas" que, neste momento, alteraremos para o "método" ou algo que equivalha à estrutura do artigo. Tendo em vista o nosso objetivo de apresentar breves considerações do paulista Mário de Andrade, expressas nos quatro artigos sobre as Letras Argentinas Contemporâneas que Mário publicou no Diário Nacional de São Paulo entre abril e maio de 1928, sobre a "Nova" Argentina das décadas de 1920 e 1930, o artigo está estruturado em três momentos principais, além da introdução e conclusão: iniciaremos com questões mais gerais, mas que compõem o "pano de fundo" deste trabalho. Nesse sentido, retomaremos algumas ideias sobre modernização, modernidade e ultraísmo tendo em vista as particularidades dos fenômenos, seus distintos desdobramentos e as respostas variadas que podem ser encontradas; em um segundo momento trataremos de algumas das respostas da vanguarda argentina a esses processos, assim como abordaremos, grosso modo, algumas das particularidades dessas respostas por meio das revistas de vanguarda - Prisma, Proa e Martín Fierro; e, por fim, estudaremos, ainda que brevemente, algumas das considerações de Mário de Andrade nos seus artigos no Diário Nacional, entre abril e maio de 1928, acerca dessas imagens, projeções e representações produzidas por uma parte da vanguarda argentina. Mais do que entrar nos minuciosos e ricos detalhes de cada artigo, entendemos os mesmos como espaços de reflexão e crítica à situação nacional brasileira.

Cabe dizer que este trabalho pode ser entendido e interpretado como um "ensaio". Desse modo, esclarecemos que não pretendemos abordar todas as "respostas" aos processos modernizantes na Argentina ou todos os detalhes dos artigos de Mário, mas sim iniciarmos uma reflexão a partir do que foi projetado e representado por parte da vanguarda argentina, sob a ótica de um paulista "moderno". 


\section{Modernidade, modernização e ultraísmo}

Segundo Berman (1986), atualmente, existe um tipo de experiência vital, de tempo e espaço e das possibilidades de vida e perigos, que é compartilhada por homens e mulheres em todo o mundo. A esse conjunto de experiências, o autor denomina "modernidade". "Ser moderno" é encontrar-se em um ambiente que promete aventura, poder, alegria, crescimento, autotransformação e transformação das coisas ao redor, sendo que, ao mesmo tempo, ameaça destruir tudo o que temos, tudo o que sabemos e tudo o que somos, enfatizando que "ser moderno" é fazer parte de um universo no qual, como disse Marx, "tudo o que é sólido desmancha no ar" (p. 15).

Faoro (1994), na segunda parte do livro "Existe um pensamento político brasileiro?" estabelece uma distinção entre a modernização e a modernidade. Segundo o autor, a modernidade, no seu processo, compromete toda a sociedade, ampliando o raio de expansão de todas as classes, revitalizando e removendo seus papéis sociais, quase como uma "lei natural", enquanto a modernização chega à sociedade por meio de um grupo condutor que procura moldar o país a partir da ideologia ou da coação, almejando uma política de mudança. Nas palavras do autor:

Na modernidade, a elite, o estamento, as classes - dizemos, para simplificar, as classes dirigentes - coordenam e organizam um movimento. Não o dirigem, conduzem ou promovem, como na modernização. A modernização, quer se chame ocidentalização, europeização, industrialização, revolução passiva, via prussiana, revolução do alto, revolução de dentro - ela é uma só, com um vulto histórico, com muitas máscaras, tantas quantas as das diferentes situações históricas (FAORO, 1994, p.3).

Desse modo, deve-se refletir e considerar o significado, as percepções e as consequências variadas da modernização e da modernidade, nos seus devidos locais.

Com relação às distintas consequências econômicas, políticas e sociais da modernidade e modernização na América Latina ${ }^{4}$, Zanetti (1994) afirma

\footnotetext{
${ }^{4}$ Segundo Rama (1984), a modernização na América Latina se inaugura por volta de 1870 e se estende até 1900 .
} 
que essas proporcionaram condições favoráveis à irradiação dos logros de um campo cultural ampliado, diversificado e complexo, que surgia em cada um dos centros hispano-americanos, sobretudo naqueles "mais modernos". Ademais, de acordo com Pizarro (2004), a modernidade na América Latina adquire um perfil periférico, pois,

(...) la complejidad de flujos culturales que se cruzan, se solapan, permanecen muchas veces aislados, se desarrollan en términos desiguales, adquieren carácter residual o emergente, se desintegran o permanecen, se mezclan, proviniendo de puntos diferentes del área, posibles tal vez de organizar para su comprensión en torno a núcleos de funcionamiento que reciben, irradian o por lo menos adquieren espesor en su geografía cultural (p.110-111).

Segundo Pizarro (2004), os "núcleos aglutinadores" são as cidades que polarizam a atividade cultural pela força do movimento que as faz emergir frente às demais e que configuram e abrigam distintos movimentos e respostas. Desse modo, Sarlo (2010) considera que o processo modernizador foi condição imprescindível para um movimento articulado, ainda que composto por diversas faces, do ponto de vista de concepções estéticas e ideológicas, com um intercâmbio e discussão entre os pares. Nesse sentido, a modernização na América Latina trouxe consigo novas regras de articulação e de consumo, com intercâmbios nos modos de consagração e dos sentimentos de pertencimento ${ }^{5}$. Como um exemplo dessas transformações, podemos destacar a Argentina e, mais especificamente, a cidade de Buenos Aires.

Buenos Aires cresceu de forma significativa nas duas primeiras décadas do século XX. Segundo Lattes e Sautu (1978), a Argentina ocupa o segundo lugar entre as nações que receberam maior imigração europeia ${ }^{6}$ nos cem anos entre a metade do século XIX e a década de 1950, o que também influenciou na série de mudanças ${ }^{7}$ que seus habitantes tiveram de processar.

\footnotetext{
5 Também neste período que a "letra" aparece como a alavanca da ascensão social, da respeitabilidade pública e da incorporação aos centros de poder (RAMA, 1984).

${ }^{6}$ Calcula-se que até 1930 a Argentina tenha recebido por volta de 6,4 milhões dos imigrantes, dos quais metade retorna ao país de origem (GALLO, 1986). Em 1936, a porcentagem de estrangeiros superava $36,10 \%$ e os homens não nativos eram $120,9 \%$ a mais.

${ }^{7}$ Entre as mudanças, destacam-se a modernização dos meios de comunicação, assim como a divulgação e massificação dos mesmos. Esses fenômenos influenciaram nas mais diversas respostas que foram produzidas pelos intelectuais.
} 
O Centenário da Independência ${ }^{8}$, em 1910, traduziu em termos ideológicos e morais as reações diante de uma população diferenciada pelos idiomas e origens nacionais, atenuada pelo rápido crescimento material da própria cidade.

De acordo com Sarlo (2010), ainda que a reflexão sobre a nação tenha sido significativa no Centenário da Independência, as décadas de 1920 e 1930 marcaram esse processo de reflexão sobre si e o "outro", o "nacional" e o "estrangeiro". É nesse contexto que podemos retomar o movimento de vanguarda argentino que, segundo Schwartz (1992), não teve um marco fundador estrondoso, como a Semana de Arte Moderna realizada em São Paulo no ano de 1922, mas teve algo equivalente ao modernismo brasileiro ${ }^{9}$, que ficou conhecido como ultraísmo ${ }^{10}$. O movimento teve início na Argentina em meados da década de 1920 a partir de Jorge Luís Borges, introduzindo

\footnotetext{
${ }^{8}$ Temas como o nacionalismo, hispanismo e arielismo passam a formar parte do horizonte ideológico do centenário (ALTAMIRANO, 1997). Entre as obras da comemoração do centenário estão: Canto a la Argentina (1910) de Ruben Darío e Odas Seculares (1910) de Leopoldo Lugones.

${ }^{9}$ De acordo com Sérgio Miceli (2010), a diferença mais gritante entre o modernismo brasileiro e o ultraísmo argentino tem a ver com a centralidade cultural de Buenos Aires, cuja hegemonia inviabiliza até hoje quaisquer pretensões de reconhecimento da atividade intelectual nas províncias. Os escritores nascidos longe da capital - como Carlos Mastronardi - não teriam persistido sem as bênçãos da capital, enquanto a predominância Rio-São Paulo em todos os domínios da atividade cultural nunca brecou os surtos regionais de criatividade intelectual, como de Pernambuco, Minas Gerais e Rio Grande do Sul. Outro contraste mencionado é o contexto político: enquanto na Argentina o golpe do Uriburu não produziu sequelas de peso na ordenação institucional do campo intelectual, a vitória da Aliança Liberal sob a liderança de Vargas alterou a conformação anterior. Em outras palavras, o arreglo argentino se contrapõe à brusca ruptura na história intelectual brasileira em 1930. Miceli considera que o vigor portenho continuou dependente dos magnatas da imprensa, enquanto, no Brasil, as políticas públicas de iniciativa governamental alteraram de modo drástico o ofício e as práticas dos intelectuais, isto é, se por um lado os intelectuais brasileiros foram brindados com posições funcionais destacadas nos altos escalões do serviço público federal, por outro ficaram reféns das oportunidades de inserção burocrática. Ademais, refere-se à distinção da origem social e dos modos de aquisição de capital cultural por parte da geração de vanguarda. Por fim, conclui: "os argentinos inventaram uma simbiose entre a matéria jornalística e o texto literário. Os brasileiros se especializaram na prestação de serviços ideológicos e políticos" (p. 16-18).

${ }^{10}$ Movimento que tem origem na Espanha, no final da década de 1910, tendo como protagonistas: Rafael Cassinos-Asséns, Ramón Gómez de la Serna, Jacobo Sureda, Gerardo Diego e Guillermo de Torre. O movimento floresceu em Buenos Aires, por volta do início da década de 1920, através de Jorge Luis Borges, que passa três anos na Espanha, publicando nos jornais madrilenos traduções de poesia expressionista de Gotfried Benn, Wilhelm Klemm, entre outros.
} 
no país a nova estética de vanguarda, que revolucionava as artes em todos os grandes centros ${ }^{11}$ :

Assim o definiu o próprio Cansinos-Asséns: "O ultraísmo é uma vontade caudalosa que extravasa todo limite escolástico. É uma orientação para contínuas e reiteradas evoluções, um propósito de perene juventude literária, uma antecipada aceitação de todo módulo novo e toda ideia nova. Representa o compromisso de ir avançando com o tempo". (BORGES apud SCHWARTZ, 1992, p. 29).

A partir do trecho extraído de Nosotros, em 1921, Borges propunha e "convidava" os demais intelectuais argentinos à "transmutação da realidade palpável do mundo em realidade interior e emocional” (p.31). Segundo Schwartz (1992), o ingresso oficial da Argentina no "universo da vanguarda"12 ocorre com a publicação, em 1921 e 1922, dos dois números da revista mural Prisma, colados nos muros de Buenos Aires por Borges, Eduardo González Lazuna, Guillermo Juan, entre outros.

A revista mural Prisma tinha como frase: "hoja mural que dio a las ciegas paredes y a las hornacinas baldías una videncia transitoria y cuya claridad sobre las casas era ventana abierta frente a cielos distintos". O objetivo da revista era continuar a linha de reformulação das chaves necessárias para a mudança de escritores consagrados, que mantinham as estruturas clássicas. As modificações relacionadas à estética e a concepção da literatura e das suas funções conduziram ao descobrimento de autores considerados "marginais" até então, que chegam a converter-se nos percursores dessa nova literatura,

\footnotetext{
${ }^{11}$ Ainda que tenha nascido na Argentina, inspirado na Espanha, o movimento não era uma cópia. As diferenças deveriam ser consideradas, como assinala Borges: "El ultraísmo de Sevilla y Madrid fue una voluntad de renuevo, fue la voluntad de ceñir el tiempo del arte con un ciclo novel, fue una lírica escrita como con grandes letras coloradas en las hojas del calendário y cuyos más preclaros emblemas- el avión, las antenas y las hélices- son decidoras de una actualidad cronológica. El ultraísmo en Bueno Aires fue el anhelo de recabar un arte absoluto que no dependiese del prestigio infiel de las voces y de hermosura. Bajo la enérgica claridad de las lámparas, fueron frecuentes, en los cenáculos españoles, los nombres de Huidobro y Apollinaire. Nosotros, mientras tanto, sopesábamos líneas de Garcilaso, andariegos y graves a lo largo de las estrellas del suburbio, solicitando un límpido arte que fuese tan intemporal como las estrellas de siempre. Abominamos los matices borrosos del rubenismo y nos enardeció la metáfora, por su algébrica forma de correlacionar lejanías" (BORGES apud MONEGAL, 1978: 20).

${ }^{12}$ Uma breve discussão sobre o termo e as condições para que a vanguarda surja será feita no próximo tópico.
} 
entre eles estão: Ricardo Güiraldes, Evaristo Carriego, Baldomero Fernández Moreno e Macedonio Fernández.

Segundo Schwartz (1992), em linhas gerais, a situação política do país era propícia às mudanças, pois com Hipólito Yrigoyen e Marcelo T. de Alvear como presidentes da nação nos anos 1916 e 1922, foi possível dar início às reformas sociais e universitárias que permitiram a participação da população argentina - ao invés de somente as forças oligárquicas - na vida nacional ${ }^{13}$. Nesse sentido, ao processo de profissionalização iniciado nas duas primeiras décadas do século XX segue-se um conjunto de detalhamento das práticas e de diferenciação de grupos.

De acordo com Sarlo (2010), a cidade passa a ser o objeto de debate ideológico-estético: sua modernização é celebrada e denunciada, busca-se um espaço perdido ou se encontra, na dimensão internacional, uma cena espetacular (p.56). Também é interessante notar o sistema de "respostas" culturais produzidos nesses anos e, pelo menos, até a década de 1950.

A autora considera como um período de incertezas e de certezas muito sólidas, de releituras do passado e de utopias, de choques entre as representações do futuro e da história nos textos e polêmicas. É por essa razão que o próximo tópico abordará algumas dessas "respostas" para, ao final, estudarmos algumas das considerações de um paulista acerca dessas representações modernas portenhas.

\section{A "nova" Argentina imaginada e projetada}

A doçura da nostalgia não nos deleita e quiséramos ver todas as coisas em primícias de floração. E ao vagar por esta única noite deslumbrada, cujos deuses magníficos são as augustas reverberações das luzes áureas, como gênios salomônicos prisioneiros em taças de cristal, quiséramos sentir que tudo nela é novo e que essa lua que surge no azul edifício não é a circular eterna palestra sobre a qual os mortos fizeram tantos exercícios de retórica, mas uma lua nova, virginal e auroralmente nova (BORGES, À margem da estética moderna).

\footnotetext{
${ }^{13}$ Do ponto de vista da política internacional, a Revolução Mexicana, o pós-Primeira Guerra Mundial e a Revolução Russa também influenciaram na evolução ideológica dos intelectuais (PIZARRO, 2004).
} 
A partir da década de 1920 e, mais especificamente, 1922, a efervescência intelectual provoca uma explosão de manifestos, editoriais, folhetos e, principalmente, revistas. Segundo Sarlo (2010), as revistas ${ }^{14}$ foram o instrumento privilegiado de intervenção do "novo cenário" que surgia. Uma vez que todo processo literário se desenvolve na relação com um núcleo estético-ideológico que o legitima - seja tradição, nacionalidade, alguma dimensão social, entre outros -, os jovens renovadores escolheram o "novo"15 como princípio de sua literatura e dos julgamentos que lançaram sobre seus antecessores e contemporâneos ${ }^{16}$, que organiza e dá significado ao conjunto de reivindicações. Em outras palavras:

O "novo" é um princípio autossuficiente para traçar as grandes linhas divisórias no campo intelectual, mas não esgota todos os conteúdos do programa com que a vanguarda intervém na conjuntura. (...) as ideologemas nacionalistas são produzidos pelos escritores da renovação, que o processam a partir da "perspectiva" do "novo" (SARLO, 2010, p. 178).

Por outro lado, o "novo" é também uma opinião sobre o público que a vanguarda ${ }^{17}$ vai dividir $^{18}$, em um movimento oposto ao de revistas como Nosotros, que se comprometeu em homogeneizar e unificar o público.

\footnotetext{
${ }^{14}$ Segundo o guia hemerográfico, Las revistas literárias argentinas (1893-1960), de Héctor René Lafleur, Sergio D. Provenzano e Fernando Pedro Alonso, na década de 1920, a Argentina teve o surgimento de 83 revistas novas.

${ }^{15}$ Cabe dizer que nem mesmo a concepção do "novo" é algo homogêneo. Por exemplo, grosso modo, o "novo" para os "vanguardistas" impõe-se na cena estética; para uma parte da esquerda, era a promessa contida no futuro - isso demonstra que os princípios de valor, em grupos distintos e mesmo dentro das denominações "esquerda" e "direita", eram diferentes (SARLO, 2010).

${ }^{16}$ Esse eixo de diferenciação opõe a vanguarda não apenas a Lugones e ao modernismo, a Galvéz e ao realismo, mas também à estrutura e à organização das instituições intelectuais (SARLO, 2010).

${ }^{17}$ Segundo Monegal (1978), Borges sempre zombou suavemente do termo "vanguardia". No artigo "La paradoja de Apollinaire", Borges escreve: "Con alguna evidente salvedad (Montaigne, Saint-Simon, Bloy) cabe afirmar que la literatura de Francia tiende a producirse en función de la história de esa literatura. Se cotejamos un manual de la literatura francesa (v.g o de Lanson ou o de Thibaudet) con su congénere británico (v.g o de Saintbury o el de Sampson), comprobaremos no sin estupor que éste consta de concebibles seres humanos y aquél de escuelas, manifiestos, generaciones, vanguardias, retaguardias, izquierdas o derechas, cenáculos y referencias al tortuoso destino del capitán Dreyfus" (p. 14).

${ }^{18}$ A esquerda cria a hipótese de um público que é preciso educar, expresso em Claridad, ou imagina um público que deve converter-se em leitor a partir de determinações sociais. Também
} 
Cabe fazermos algumas considerações acerca da vanguarda argentina. De acordo com Sarlo (1997), diferentemente da vanguarda europeia - que tinha sua "verdade" na radicalidade estética, moral e social -, a Argentina buscava sua "verdade" no sistema literário e no espaço sociocultural respectivo do qual rompe: "el cambio de las formas y la transformación de los costumbres literarias se manifiesta como "vanguardia" cuando existen actores y relaciones institucionales que pueden definirse como propios de un campo intelectual desarrollado" (p.212).

Ou seja, esse campo intelectual não se produz no vazio social, ao contrário, encontra nas formas sociais de produção literária as condições para a sua realização. A ruptura da vanguarda afeta o conjunto das relações intelectuais - as instituições do campo intelectual e as funções socialmente aceitas por seus atores. Sarlo (1997) afirma que, em suma, todas as modalidades de organização material e ideológica são afetadas pela vanguarda.

Sarlo (2010), baseando-se na carta publicada na revista Poesia de Macedonio Fernández para Pedro Vignale, escreve:

Se o modernismo e o decadentismo haviam difundido formas caracterizadas por fortes vínculos sensoriais, a vanguarda trabalhava para destruí-los. O que constituía, no modernismo, uma estratégia de ampliação no sentido da legibilidade, na renovação são operações que delimitam o campo e afirmam a legibilidade como não valor (p.180).

As opções estéticas atingem não só a produção literária, como também a recepção e as expectativas dos leitores. Nas revistas se processavam os tópicos e se definiam os obstáculos que os movimentos de renovação ou democratização da cultura argentina enfrentavam. Do mesmo modo, conflitos sociais espalhavam seus "fantasmas" sobre os debates culturais e estéticos: a questão da língua (o "castelhano aceitável” na fala e na escrita), das traduções

para a vanguarda estão os "filisteus", os artistas acadêmicos e os tradicionalistas, que não querem arriscar uma arte pouco imaginável com os sentidos, e do outro, o novo leitor, com um perfil imaginário. Nesse sentido, Sarlo (2010) considera que a vanguarda dos anos 1920 não é pedagógica, pois, mais do que educar, mostra, exibe-se e provoca. 
(quem e por que está autorizado a traduzir), do cosmopolitismo ${ }^{19}$ (qual é o internacionalismo "legítimo"), do criollismo (quais formas respondem à nova estética), da política (qual é a posição da arte, o papel do intelectual), entre outros (SARLO, 2010).

A primeira dessas revistas - após a Prisma - foi a Proa, dirigida em sua primeira fase (1922-1923) por Borges, Eduardo González Lanuza e Francisco Piñero e na segunda fase (1924-1926) por Borges, Alfredo Brandán Caraffa, Ricardo Guiraldes e Pablo Rojas Paz. O tom do período foi expresso nas palavras de Eduardo González Lanuza, na revista Prismas:

Eu não hei de anunciar meu coração qual mercadoria, nem hei de fazer piruetas para cativar tua atenção dispersa no caleidoscópio vário de teu viver [...]. Se buscas a bazófia de todos os dias, tira uns níqueis do bolso e compra alguma revista; mas este livro está sobrando em tuas mãos (LANUZA, 1924, p. 7-8).

Do mesmo modo, o objetivo ou a intenção da revista foi expresso por Borges, na primeira edição da segunda fase da revista:

Proa surge em meio a um florescimento insólito. Jamais nosso país viveu a vida do espírito tão intensamente como agora. A alta cultura, que até hoje tinha sido patrimônio exclusivo da Europa e dos poucos americanos que tinham bebido nela, começa a transmutar-se em forma milagrosa, como produto essencial de nossa civilização (...). A Proa quer ser uma tribuna ampla e sem barreiras. Crisol de juventudes que amam o heroísmo obscuro e cotidiano, ela pretende plasmar em Academia a energia dispersa de uma geração sem rancores (BORGES apud SCHWARTZ et al., 1992, p. 31-33).

\footnotetext{
${ }^{19}$ A dialética do localismo e do cosmopolitismo gerou uma polêmica-atualmente antológica- entre os escritores argentinos dos grupos antagônicos "Boedo" e "Florida", nomes correspondentes às ruas de Buenos Aires com características sociais bem diferentes. Em linhas gerais, o Boedo representa o setor urbano, vinculado à periferia e ao proletariado, agrupando os escritores com preocupações literárias socializantes, interessados na obra de arte pelo conteúdo do que pela ordem formal. Como representantes desse grupo estavam as revistas Renovación, Los Pensadores, Claridad e La Campana de Palo. O grupo Florida, por outro lado, tem como preocupação maior a incorporação ao panorama cultural argentino dos novos valores estéticos da vanguarda europeia, tanto na literatura como nas artes plásticas, música e na arquitetura. Como representantes desse grupo estavam os martinfierristas, assim como as revistas Prisma e Proa (SCHWARTZ, 1991).
} 
O texto coletivo que se abre na segunda fase da revista declarava a independência do grupo em relação aos "velhos mestres" e registrava os efeitos da Guerra Mundial, que modificou todas as estruturas e instituições. Proa era uma frente caracterizada pelo espírito renovador e pela juvenilidade. Segundo Sarlo (2010), o texto inicial da revista tem ecos e inflexões arielistas ${ }^{20}$ : fervor, afirmação moral, espírito de seriedade e unidade de aspirações.

De acordo com Achugar (1994), a revista apresentava um internacionalismo mais ligado ao arielismo, isto é, a América Hispânica tem um lugar mais destacado ${ }^{21}$. Proa também incluía um nacionalismo cultural de "novo tipo" - encabeçado pela versão borgiana do criollismo -, organizava estratégias para demonstrar a função da literatura europeia no contexto da renovação rio-platense e preocupava-se com as questões do idioma. Outro elemento marcante da revista eram as ilustrações de Norah Borges, Figari, entre outros; os desenhos de Gustavo Klimt; caricaturas de inspiração cubista de Salgueiro Dela-Hanty, entre outros. No fundo, segundo Sarlo (2010), a revista preocupava-se em redefinir o espaço da literatura argentina.

Segundo Schwartz e Alcalá (1992), se Prisma e Proa ${ }^{22}$ significaram o ponto de partida das revistas de vanguarda, coube a Martín Fierro ${ }^{23}$ (1924-1927), sob a direção de Evar Mendéz durante 45 edições e idealizada por Oliverio Girondo ${ }^{24}$, consolidar o movimento. Matizada entre o nacionalismo e o

${ }^{20} \mathrm{O}$ termo se refere à tendência cultural, nacionalista e latino-americanista de fins do século XIX, cujo principal expoente é o uruguaio José Enrique Rodó, com sua obra Ariel (1900).

${ }^{21}$ Exemplo disso é a publicação, no número 10 da segunda fase, da fundação da Unión LatinoAmericana, com os seguintes dizeres: "Desenvolver, nos povos latino-americanos, uma nova consciência dos interesses nacionais e continentais, auspiciando toda renovação ideológica que conduza ao exercício efetivo da soberania popular, combatendo toda a ditadura que crie obstáculo às reformas econômicas inspiradas pelos anseios de justiça social (...) " (PROA, no 10 , 1925: 65-66).

${ }^{22}$ Também devemos mencionar, em 1923, a publicação da revista Inicial com Roberto Ortelli, Brandan Caraffa e González Tunon e de Valoraciones, do grupo Renovación de La Plata que irá até 1928.

${ }^{23} \mathrm{O}$ nome da revista faz referência ao grande herói da literatura gauchesca do século XIX, cantado no poema épico de José Hernandez. No entanto, o nome da revista, que tem como pano de fundo o "nacionalismo cultural", se deve ao fato de que, antes da fase vanguardista, a Martín Fierro fora publicada por um breve período - apenas três números - em 1919, sob a direção de Alberto Ghiraldo.

${ }^{24}$ Demais fundadores da revista: Ernesto Palacio e Pablo Rojas Paz. 
cosmopolitismo, a revista publicou artigos sobre pintura, música e cinema. Segundo Sarlo (1997), a partir de testemunhos sobre o periódico, a revista foi considerada uma vanguarda eclética, a qual: "fue una espécie de cóctel de la nueva generación. No había mayor selección. Estaban todas las tendencias pero predominaba la superficialidad combativa" (CARRAFA, El Clarín, 1977).

Seu perfil vanguardista delineou-se com clareza, no quarto número, quando foi publicado o Manifesto de Martín Fierro, redigido por Girondo:

Ante o receituário que inspira as lucubrações de nossos mais "belos" espíritos e o gosto pelo anacronismo e pelo mimetismo que demonstram. Ante a ridícula necessidade de fundamentar nosso nacionalismo intelectual, enchendo valores falsos que à primeira alfinetada murcham como balões (...). Martin Fierro sente a necessidade imprescindível de se definir e de chamar quantos sejam capazes de perceber que nos encontramos na presença de uma nova sensibilidade e de uma nova compreensão que, colocando-nos de acordo com nós mesmos, nos descortina panoramas insuspeitados e novos meios e formas de expressão (...). Martín Fierro sabe que "tudo é novo sob o sol" se se olha com pupilas atuais e se expressa com um acento contemporâneo (GIRONDO apud SCHWARTZ, 1994, p. 115).

A partir do manifesto, nota-se que a tradição ${ }^{25}$ e a "novidade" se conjugam a fim de trazer uma reflexão sobre o cosmopolitismo:

Afirmación de la novedad como valor y remisión a una tradición cultural preexistente, reivindicación de lo "característicamente argentino" y perspectiva cosmopolita. Con estos elementos se construye ese compuesto ideológico-estético que es el martinfierrismo y, en general, la vanguardia del veinte. La tensión populismo/ modernidad o nacionalismo/cosmopolitismo informa acerca de un hecho significativo, casi una constante de la cultura argentina del siglo XX (SARLO, 1997, p. 253).

\footnotetext{
${ }^{25}$ A tradição da revista também pode ser notada no número 22, quando Girondo propõe uma campanha para um monumento a José Hernandez, devendo receber a adesão de todos os artistas. Os nomes dos artistas de "tradição" - como, por exemplo, Eduardo Wilde e Rojas Paz são propostos várias vezes pela revista (SARLO, 1997).
} 
Ademais, a necessidade de ser "moderno" não implicava, necessariamente, abandonar o nacional, porque, antes de pensar no "internacional”, era preciso ser gaúcho/ argentino ${ }^{26}$. Nesse sentido, pode ser que Girondo compartilhasse com Mariátegui a seguinte afirmação: “(...) por estes caminhos cosmopolitas e ecumênicos, de que tanto nos criticam, vamos nos aproximando cada vez mais de nós mesmos ${ }^{27 " ~(M A R I A ́ T E G U I ~ a p u d ~ S C H W A R T Z, ~ 1995, ~ p . ~ 473) . ~}$

Isto é se valer das conquistas europeias e norte-americanas em favor do "bem-estar" argentino. Nas palavras de Mariátegui:

Mas para estabelecer mais exata e precisamente o caráter nacional de todo vanguardismo, voltemos à nossa América. Os novos poetas da Argentina constituem um interessante exemplo. Todos eles estão nutridos da estética europeia. (...) Não obstante esta impregnação de cosmopolitismo, não obstante sua concepção ecumênica da arte, os melhores destes poemas vanguardistas continuam sendo os mais argentinos. A argentinidade de Girondo, Guiraldes, Borges etc. não é menos evidente do que seu cosmopolitismo. O vanguardismo literário argentino denomina-se "martinfierrismo". Quem alguma vez tenha lido o periódico desse núcleo de artistas, Martín Fierro, terá encontrado nele, ao mesmo tempo que os mais recentes ecos da arte ultramoderna da Europa, os mais autênticos sons gaúchos (MARIÁTEGUI apud SCHWARTZ, 1995, p. 474).

De acordo com Sarlo (1997), a aparição da revista Martín Fierro, em fevereiro de 1924, marcou no campo intelectual argentino uma forma de ruptura estética tipicamente moderna: a da vanguarda. Desse modo,

\footnotetext{
${ }^{26}$ É interessante lembrar de Borges, ainda na década de 1920 e 1930, quando tentou definir em seus poemas, na prosa de seus ensaios, na biografia do poeta popular Evaristo Carriego e até nos seus primeiros ensaios de ficção costumbrista: "Hombres pelearon" de 1928 e "Hombre de la esquina rosada" de 1933 um criollismo essencial, não acidental, que vem da herança cultural argentina e também da biografia e do sangue do poeta popular. Segundo Monegal (1978), esse criollismo não nega a herança europeia, mas a transforma através de experiências do poeta no tempo (a História ainda viva) e no espaço (o pampa e o subúrbio que descobre nas beiras da cidade moderna que já é Buenos Aires) (p. 23).

${ }^{27}$ De acordo com Susana Zanetti (1994), a residência em Paris contribuía para descobrir ou assumir a condição hispano-americana, assim como a pensá-la em sua dimensão literária, utilizandose dos escritos de Ugarte: "Nuestra generación se definió em Iberoamérica pronunciando el nombre de dos ciudades: París, Madrid...Al instalarmos en Madrid (punto de partida) y París (ambiente español) descubrimos dos verdades. Primera, que nuestra producción se enlazaba dentro de una solo literatura. Segunda, que, individualmente, pertenecíamos a Iberoamérica desde Europa en forma panorámica" (p. 525-526).
} 
Martin Fierro propuso una ruptura com las instituciones y costumbres de un campo intelectual preexistente, cuyo desarrollo fue el que hizo socialmente posible el surgimiento de la vanguardia. Incluso algunas formas típicas de las costumbres literarias de los años que preceden y siguen al Centenario (...) (SARLO, 1997, p. 216).

Nesse sentido, desde a sua fundação, quando se tratava do "sistema de consagração", a revista criticava Nosotros. Para Martín Fierro, a revista Nosotros "representa una replicación, cuando no una agencia, en el campo intelectual, del sistema oficial de consagración y de sus criterios estéticos".

Para além dos confrontos entre as revistas e os intelectuais, deve-se pensar no significado e nas mais diversas "respostas" que foram dadas a esse cenário tão rico e complexo. Concordamos com Sarlo (2010) ao escrever que a "modernidade é um cenário de perdas, mas também de fantasias reparadoras. O futuro era hoje" (p.57).

Claramente, esse tópico não teve e nem conseguiria abordar todas as especificidades dos debates e das revistas. O nosso objetivo foi dar luz a algumas das questões mais comentadas nas revistas, pelas vanguardas, que servirão para nortear o próximo tópico.

É a partir do que foi imaginado e projetado nestas revistas - mas não exclusivamente por elas - que Mário de Andrade escreve, por vezes admira, e reflete sobre a "novidade" portenha e, em alguns momentos, estabelece um diálogo com alguns intelectuais argentinos.

\section{A "nova" Argentina sob as lentes paulistas}

Me parece que nenhuma figura representa mais integralmente que Ricardo Guiraldes o período psicológico nacional que estão atravessando com maior ou menor intensidade as nações sulamericanas. Já afirmei que a diferença psicológica atual entre brasileiros e argentinos significava mais que simples descendência racial e circunstâncias sociais diferentes. Significava que as duas nacionalidades já possuíam uma entidade psicológica constante (...). Porém todos dentro do mesmo turtuveio entre a atração e influência europeia, e uma fatalidade nacional certa mas sem nitidez ainda, quase miragem, por ser baseada no futuro (ANDRADE, Diário Nacional, 13 de maio de 1928). 
Segundo Antelo (1986), é por volta de 1925 que Mário encontra-se empenhado em elaborar um conceito de vanguarda que reunisse a liberdade estética e a responsabilidade do intelectual. Nessa busca, que o autor denominou "organicidade", Mário vai tentar se informar da maior quantidade de experiências coincidentes tentadas na América Latina. Uma das que mais lhe desperta atenção é o ultraísmo argentino que tinha, como seu maior símbolo, o periódico Martín Fierro (1924-1927):

É precisamente em 1925 que Mário de Andrade toma contato com o grupo Martín Fierro, a partir do número 20 da revista. Podese supor que daí tenha surgido o interesse por Bazar (1922) de Francisco Luiz Bernárdez e por quatro textos, publicados em 1925. São eles: Alcándara do mesmo Bernárdez, Calcomanías e Veinte poemas para ser leídos en el tranvia de Oliverio Girondo e as Inquisiciones de Jorge Luis Borges (...). À leitura de Bernárdez, Borges e Girondo, deve-se acrescentar o panorama que lhe oferecem as duas antologias da poesia argentina da geração de 22, a Antologia de la poesia argentina moderna de Julio A. Noé e a Exposicion de la actual poesia argentina (1922-1927) de Pedro J. Vignale e César Tiempo (ANTELO, 1986, p. 26).

Apesar das leituras dessas obras, a partir dos arquivos de Mário de Andrade, Antelo (1986) considera Martín Fierro como guia crítico. Exemplo disto é a anotação na página de anterrosto de Antologia de Noé: "Crítica do livro em Martín Fierro, 1926, maio" (p.27).

Segundo Monegal (1978), o documento mais importante para a reconstrução do aspecto das relações entre o modernismo brasileiro e o ultraísmo argentino é a série de quatro artigos sobre as leituras argentinas contemporâneas que Mário publicou no Diário Nacional de São Paulo, entre 22 de abril e 20 de maio de 1928.

$\mathrm{O}$ primeiro dos quatro artigos foi dedicado à "Literatura Modernista Argentina" (22 de abril de 1928) e esteve orientado, sobretudo, para mostrar a diferença entre as literaturas argentina e brasileira. Mário de Andrade (1928) assinalava que podemos recriar pela inteligência as causas e os elementos que levaram o outro país a adquirir o ritmo mais forte que organiza a literatura modernista. No entanto, assegurava que como o ritmo não era o da "gente" e não interessava como ajuda ou complemento, não fazia parte de nós mesmos. Ainda segundo Mário, isso decorria de certos ideais americanistas e latino-americanistas, que não despertavam interesse 
aos intelectuais de ambas as partes:

Tenho horror a essa história de "América Latina" muito agitada hoje em dia. "Hispano Americanismo, cuantas estupideces se hacen y dicen en tu nombre!" (Martín Fierro). Tenho horror ao Pan-americanismo. Noções, aliás, que na Europa já acharam rival na idealizada República Europeia..Não existe unidade psicológica ou étnica continental. Mesmo aceitando só para argumentar que as condições históricas e econômicas sejam absolutamente iguais nos países de um continente, isso não basta para a criação de um conceito social continental porque não são condições permanentes nem intrínsecas (ANDRADE, Diário Nacional, 22 de abril de 1928).

No fundo, Mário quis demonstrar que, naquele momento, o nacionalismo dominava. E o que lhe incomodava ao ler, estudar e conhecer o movimento argentino era que no país vizinho havia uma "inconsciência nacional" ou, em outras palavras, um "nacionalismo natural”, devido à força concentradora e unidade geográfica de Buenos Aires, expresso na literatura:

Quando já falam que a Argentina é um grande país e Buenos Aires uma grande capital, falam duas verdades incontestáveis. Isso dá aquela calma necessária de si mesmo, aquela confiança na terra e no patrício que são os elementos mais úteis para a determinação, firmação e permanência dos caracteres psicológicos. Ninguém é tão si mesmo como em casa (...) O argentino, consciente da grandeza dele e auxiliado por ela, já possui a confiança de quem está na própria casa e a calma de quem está no próprio quarto. Pouco se amola desse argentino de dentro possuir tal dose de italiano, tal dose de espanhol (...). Tudo isso já é para ele mais ou menos indiferente. Não porque raciocine que de fato as entidades nacionais coincidem em vários pontos, mas porque está bem seguro de si. Mesmo ele quase nunca matuta sobre isso porque não carece mais de reagir (ANDRADE, Diário Nacional, 22 de abril de 1928).

Mário comparou e criticou os brasileiros que estavam "muito conscientes" de sua condição, com um "nacionalismo desbragado" e, por vezes, um "patriotismo de bafafá”, decorrente de diversos fatores e, especialmente, da variação geográfica e da "desarmonia de progresso formidanda". A partir dessas observações e dos 
nomes das obras e revistas modernas na Argentina e no Brasil ${ }^{28}$, concluiu: "Ora, a confiança do argentino e a insegurança do brasileiro caracterizam o jeito diferente com que estão sendo tratadas as falas nacionais”.

Partindo da ideia de que o brasileiro possui uma psicologia própria e que o fato foi verificado, Mário acreditava que isso facilitaria e tornaria ridículos aqueles que vivem de patriotada em patriotada gritando: "Eu que sou brasileiro!", "Eu é que estou sendo brasileiro", sem a mínima compreensão humana, nem da vida e nem do Brasil. Antes de encerrar, criticou novamente os regionalistas, enfatizando que "não basta a gente condimentar a escritura com a especiaria d'um modismo vocabular para que o prato seja tutu. Continua cozido e não tutu". Encerrando o artigo dizendo que "o Brasil não foi feito por ninguém, Brasil é uma fatalidade que a gente pode melhorar ou piorar, esfacelar ou conservar, com psicologia já própria e fatal, através e apesar de todas as pesquisas conscientes".

Ao fim do primeiro artigo, Mário desculpa-se por não ser um especialista na matéria. Contudo justificou o "risco", pois é "sob muitos aspectos notável e digna [a literatura] de ser mais conhecida aqui". Desse modo, em seu segundo artigo, Mário esboçou um panorama rápido das revistas literárias argentinas, inserindo-as no contexto argentino, citando seus nomes mais ilustres e trechos de suas obras. Ao falar de revistas como Claridad e Martín Fierro e dos grupos que compõem cada uma das revistas, estabeleceu novamente uma comparação entre as vanguardas brasileira e argentina e demonstrou um conhecimento significativo de intelectuais argentinos:

Ao passo que a nossa poesia modernista ia tomar uma feição eminentemente rapsódica, a argentina assumia desde logo um caráter intrinsicamente literário. Tipográfico mesmo. Até dentro do Ultraísmo e da metáfora organizada em preceito os argentinos

\footnotetext{
28 "Aqui, tivemos Terra Roxa e temos Verde. Aqui possuímos gente "verde", gente "verdeamarela", gente "pau-brasil". E há livros que chamam-se Meu, Raça, Toda a América, Pau Brasil, Minha Terra, Terra Impetuosa, Coração Verde, Canto da Raça, Este é o canto da minha Terra, Brás, Bexiga e Barra Funda, entre outros. Os argentinos secundam, no geral, com La Musa de la Mala Pata, El Contador de Estrellas, Terremotos y otros Temblores, El puñal de Orion, Oasos en la Sombra, Inquisiciones, Naufragios, entre outros." (ANDRADE, Diário Nacional, 1928). Cabe dizer que segundo Monegal (1978), Mário cometeu um delicado equívoco ao considerar Martín Fierro como uma questão nacionalista e não política. De acordo com Monegal (1978), o que interessava aos fundadores era a atitude do poeta "gauchesco" e do seu personagem ao "cantar opinando".
} 
fogem da poesia oratória. Com exceção de Ricardo Guiraldes (poemas em prosa de Xaimaca) e Jorge Luis Borges, que muitas vezes a gente percebe gozando com o valor musical das palavras e oral da frase (ANDRADE, Diário de Notícias, 29 de abril de 1928).

Seguindo o interesse pelos intelectuais argentinos e por suas revistas, o terceiro de seus artigos tratou especificamente da revista Martín Fierro e de sua função "orientadora e selecionadora" de ideias e valores caracteristicamente modernistas ${ }^{29}$ : "Por todas estas razões Martín Fierro ajunta o que tem de melhor a literatura moderna argentina e representa com largueza o caráter e o espírito dessa literatura".

Por outro lado, o paulista demonstrou certo descontentamento com os últimos números da revista, pois foram compostos por muitos nomes estrangeiros, especialmente europeus e franceses. Justificou a afirmação dizendo que aqueles que se interessavam pela manifestação argentina de arte ficavam prejudicados em número, isto é, deixa-se menos espaço para os intelectuais da região em razão dos europeus que, segundo ele, liam revistas europeias com mais seriedade do que uma sul-americana: "Em geral é escrita pour l'Amerique Latine".

Apesar desse descontentamento, Mário continuou com a ideia de que a revista esboçava a força nacional e demonstrava, a partir da vibração argentina, um ritmo psicológico único, tal como explicitado no primeiro dos artigos de 1928. Desse modo, retomou a ideia de que o nacionalismo argentino era mais inconsciente do que rotular, vide a pouca frequência do problema "nacional" nas páginas de Martín Fierro e a "importância sem importância que a ele parecem dar na revista". Outro exemplo desse inconsciente era o "criollismo essencial", o qual também lhe pareceu menos tendencioso que inconsciente e mais ativo do que rotular - quase como uma fatalidade nacional que se encontra nas obras de Guiraldes, Oliverio Girondo e especialmente na obra de Borges - e pelo qual demonstrou profunda admiração:

Este poeta e ensaísta me parece a personalidade mais saliente da geração moderna da Argentina. Depois de Ricardo Guiraldes- o que teve a felicidade de morrer depois da obra prima- a figura de

${ }_{29}$ É interessante notar que, embora o modernismo nos países hispano-americanos tenha ocorrido anos antes, Mário refere-se à vanguarda argentina como modernista. 
Jorge Luis Borges é a que mais me atrai e me parece mais rica de lá. Será talvez ele quem vai substituir Ricardo Guiraldes e consolar com uma presença de intimidade a memória do morto (ANDRADE, Diário Nacional, 13 de maio de 1928).

Segundo Monegal (1978), o que Mário reconheceu foi a natureza profunda e não ostentosa do criollismo de Borges, sua radicação essencial em um solo cultural que era seu por direito de nascimento e ocupação e que jamais poderia ser extinto pelas capas de cultura estrangeira que também recobriam e adubavam este solo. Mário considerou certo ceticismo decadente de Borges decorrente da cultura excessiva para idade que tinha: 28 anos.

No restante do terceiro artigo, Mário citou e analisou outros poetas e pensadores do grupo Martín Fierro, como: Sergio Piñero, Leopoldo Marechal, Norah Lagne, Nydia Lamarque, Nicolás Olivari e Oliverio Girondo, sendo que a nenhum dedicou os elogios e a atenção concedidos a Borges. Encerrou esse artigo considerando a série escrita por ele como uma passagem, com sensação de leitor estrangeiro, no sentido de que estrangeiro compreende apenas uma psicologia étnica diferente, pois:

(...) no resto, não me considero estrangeiro para ninguém. Aqui no Brasil a palavra "estrangeiro" só é conhecida pelos semicultos. Meu povo só fala em "estranhos". Naqueles que a gente estranha um bocado pelo modo de falar e de sentir. É como estranho que escrevi tudo isto. Minha intenção foi apenas vulgarizar aqui nomes de valor que não cedem a muito nome europeu que vem na capa tradicionalmente comprada do livro francês, inglês e italiano (ANDRADE, Diário Nacional, 13 de maio de 1928).

Cabe mencionar a interessante, porém breve, análise que Mário fez sobre a literatura da "América", os intelectuais e a sua participação, ainda que em menor número, mas em igualdade de valores, no movimento do mundo. Segundo Mário (1928), a literatura modernista argentina produziu a obra de Guiraldes e, com as outras literaturas, indicou uma força nova que aparece para a mocidade cantando o lindo verso de Raul Gonzalez Tuñon: "Soy um gran pedazo de juventude".

O quarto e último artigo foi dedicado a Ricardo Guiraldes. Mário (1928) considerou o autor de Don Segundo Sombra como a figura que mais representava o período psicológico nacional, com mais ou menos intensidade, que estavam atravessando as nações sul-americanas: 
Acho que ninguém representa talqualmente Ricardo Guiraldes o momento psicológico sul-americano justamente porque ninguém como nele não se ajuntaram tão conscientemente tão equilibradamente e bem aceitas as duas tendências em que a gente se debate: atração da França e atração nacional. De toda a obra dele pequena e desigual (desconheço Rosaura, edição fora do mercado) se salientam pelo valor duas: Xamaica e Don Segundo Sombra. A primeira representa o predomínio da influência francesa, obra requintadíssima. A segunda é um equilíbrio perfeito entre as duas tendências mas tendo como base fatalizada o ideal nacional (ANDRADE, Diário Nacional, 20 de maio de 1928).

Mais uma vez Mário retomou a questão nacional e a dificuldade das nações sul-americanas em lidar com o problema: nacional/ internacional, tradição/ modernidade, e assim por diante. Posteriormente, fez uma análise minuciosa destas duas obras: Xamaica (1923) e Don Segundo Sombra (1926), e de outras como: Cuentos de Muerte y de Sangre (1915), El Cencerro de Cristal (1915), Raucho (1917). Mais do que mencionar as minúcias apresentadas por Mário, cabe refletirmos a respeito do significado, aos olhares de Mário, de Guiraldes para a "mocidade argentina":

A influência dele foi não de modelo mas de espelho. Quem olha no espelho se enxerga a si mesmo. Libertando a gente nova argentina dum passado falso ele fez mais do que dar a atualidade, de presente para esses moços. Lhes deu a realidade. Alguns a falsificaram de novo. A culpa não é nem dele nem deles. A falsificação faz parte da existência. É ela que justifica as coisas autênticas. E bom número dos poetas de hoje, por essa influência de espelho que Ricardo Guiraldes teve, gozam na Argentina a lealdade de indivíduos e de nacionais (ANDRADE, Diário Nacional, 20 de maio de 1928).

Segundo Antelo (1986), há uma diferença entre o nacionalismo de Borges e o de Mário. Por um lado, temos um nacionalismo que pensa o espaço como um âmbito reservado e restrito e que concebe o tempo ciclicamente. Nesse sentido, Borges passa por uma fase criollista, na qual o nacionalismo é concebido como categoria estética, um princípio que estabelece compromissos com o literário de uma maneira exclusiva, negando a vinculação com a história (p.49). Por outro lado, o nacionalismo de Mário, em 1928, estava em transição de uma fase ufanista e aproblemática para uma em que ele se vincula à sociedade de classes, como instrumento para 
a luta por uma nova hegemonia. Antelo (1986) denominou "nacionalismo representativo".

Foi inserido nesse "nacionalismo representativo" que Mário escreveu os artigos do Diário Nacional. Apesar das diversas interpretações que podem ser produzidas a partir desses artigos, quisemos considerá-los como espaço de reflexão e crítica para pensar a situação nacional brasileira, ainda que brevemente, naquele período. Por outro lado, também é interessante notarmos os olhares e as percepções de um paulista, alguém externo, frente ao movimento argentino, que nem sempre foi notado pelos próprios argentinos dessa forma.

\section{Considerações Finais}

O que Xul mescla em seus quadros também se mescla na cultura dos intelectuais: modernidade europeia e especificidade rio-platense, aceleração e angústia, tradicionalismo e espírito renovador; criollismo e vanguarda. Buenos Aires: o grande cenário latinoamericano de uma cultura de mescla (SARLO, 2010, p. 32).

De acordo com Sarlo (2010), no século XIX, a Argentina era uma causa e um programa. Na terceira década do século seguinte, o país surgiu como um problema que admitia poucas soluções otimistas. Ainda segundo Sarlo (2010), as sínteses estéticas do Centenário da Independência - resolução da unidade racial, cultural e linguística - não convencem nos anos 19201930. Por essa razão, o movimento da vanguarda argentina será significativo do ponto de vista das mais diversas "respostas", pois o que se tinha era um objeto multifacetado com possibilidades de olhares e perspectivas de análise diversas, algo que Sarlo denominou "cultura de mescla".

Segundo Pimentel (2010), os estudos sobre cidades e encontros culturais no século XXI, ainda que continuem sob a ideia do espírito moderno que movera os surtos de reurbanização nas cidades latino-americanas, reaparecem com uma grande diferença: a revisitação é crítica, não mais fascinada. Pimentel (2010) considera que, mais do que isso, os intelectuais queriam descobrir os impasses e as dificuldades que acompanharam o ingresso das capitais em um mundo radicalmente moderno.

A distância temporal e a "fascinação" do momento certamente influenciaram a breve análise de Mário de Andrade sobre o período e 
o que o caracterizava. Enquanto alguns intelectuais argentinos estavam desacreditados em uma "solução" do problema argentino, Mário acreditava que a Argentina era um exemplo da "inconsciência nacional" e de certa "conformidade" de culturas tão distintas. Mais do que identificar os diferentes olhares e vozes para o "mesmo" objeto, procuramos estudar e refletir, ainda que brevemente, uma parte da história das transformações de Buenos Aires nos anos 1920 e 1930 e seus desdobramentos para outros espaços, sob o olhar de um paulista "moderno".

Entre esses espaços destacamos o Brasil, um país que também contava com intelectuais das mais diversas vertentes, com suas inquietações, críticas e "respostas" diante do cenário mundial, que foram ainda mais fortalecidas pelo Centenário da Independência e pelo modernismo. Assim como na Argentina, o Centenário da Independência também é fundamental para a história brasileira, pois a questão "Que país é esse?" retorna às "cabeças e bocas" de grande parte dos intelectuais, ainda que incentivados pelas comemorações do governo. O 7 de setembro de $1922^{30}$ pôde articular presente, passado e futuro ao ensejar o balanço obrigatório dos acontecimentos passados, a avaliação dos feitos presentes e a perspectiva de realizações futuras do país. O grande anseio e tarefa dos intelectuais era conhecer o país, "criar" a nação, "forjar" a identidade nacional e "construir" o Brasil moderno (MOTTA, 1992). No mesmo ano também ocorreu a Semana de Arte Moderna, marco do modernismo no Brasil, composta por intelectuais de diversas vertentes que elaboraram uma série de "retratos" ou respostas para esboçar aquilo que constituiria a verdadeira "realidade brasileira".

É dentro desse contexto que o olhar de um paulista "moderno" para Buenos Aires está inserido. Percebemos os artigos de Mário como um espaço de reflexão para as questões nacionais e, por outro lado, como um momento interessante de diálogo entre as literaturas brasileira e argentina. Neste sentido, encerramos este ensaio com uma reflexão de uma das interpretações do passado a fim de buscar seus desdobramentos no presente, seja do ponto de vista político ou cultural.

\footnotetext{
${ }^{30}$ Segundo Maria Lígia Prado (2009), o discurso oficial do governo manteve as grandes linhas de interpretação forjadas no século XIX, isto é, da harmonia dos opostos, da unidade e grandeza do território brasileiro. Nesse sentido, a independência, o Império e a República foram passos diferentes de uma evolução "natural" e benéfica. Exemplo disso foi dado em 1921, em que o presidente Epitácio Pessoa, sob o pretexto do centenário da Independência "pacífica", pediu o translado dos despojos do último Imperador, Dom Pedro II e da Imperatriz Tereza Cristina.
} 


\section{Referências}

ACHUGAR, Hugo

(1994). "La hora americana o El discurso americanista de entreguerras". In: Ana Pizarro (org.); América Latina: palavra, literatura e cultura. vol 2. São Paulo: Memorial; Campinas, Ed.Unicamp, p. 635-662.

ALTAMIRAN0, Carlos

(1997). "La Argentina del Centenario: campo intelectual, vida literariay temas ideológicos". In: Carlos Altamirano; Beatriz Sarlo; Ensayos argentinos: de Sarmiento a la vanguardia. Argentina: Ariel, p. 161-197.

ANDRADE, Mário

(1928). "Literatura Modernista Argentina". Diário Nacional. São Paulo, 22 de abril.

(1928). "Literatura Modernista Argentina". Diário Nacional. São Paulo, 29 de abril.

(1928). "Literatura Modernista Argentina". Diário Nacional. São Paulo, 13 de maio.

(1928). "Literatura Modernista Argentina". Diário Nacional. São Paulo, 20 de maio.

ANTELO, Raúl

(1986). Na ilha de Marapatá: Mário de Andrade lê os hispano-americanos. São Paulo: HUCITEC; INL, Fundação Nacional Pró Memória.

\section{ARTUND0, Patrícia}

(2004). Mário de Andrade e a Argentina: um país e sua produção cultural como espaço de reflexão. São Paulo: Editora Universidade de São Paulo.

BERMAN, Marshall

(1986). Tudo que é sólido desmancha no ar. A aventura da modernidade. São Paulo: Cia das Letras.

FA0R0, Raymundo

(1994). Existe um pensamento político brasileiro? São Paulo: Editora Ática.

GALL0, Ezequiel

(1986). “Argentina: society and politics, 1880-

1916". In: Leslie Bethell (org.); The Cambridge
History of Latin America. Vol.5. Cambridge: Cambridge University Press, p.359-392.

LAFLEUR, Héctor René; PROVENZANO, Sergio; ALONSO, Fernando Pedro (1962). Las revistas literarias argentinas (1893-1960). Buenos Aires: Ediciones Culturales Argentinas.

LANUZA, Eduardo González

(1924). Prismas. Buenos Aires: Samet, p. 7-8.

LATTES, Alfredo Enrique; SAUTU, Ruth

(1978). "Inmigración, cambio demográfico y desarollo industrial en la Argentina". Cuadernos del CENEP, n. 5.

MICELI, Sergio

(2010). “0 enigma portenho". In: Beatriz Sarlo (Org.); Modernidade Periférica: Buenos Aires 1920 e 1930. São Paulo: Cosac Naify.

MONEGAL, Emir Rodríguez

(1978). Mário de Andrade/Borges. Um diálogo dos anos 20. São Paulo: Editora Perspectiva.

MOTTA, Marly Silva da

(1992). A nação faz cem anos: a questão nacional no centenário da Independência. Rio de Janeiro: Editora FGV, CPDOC.

PIZARRO, Ana

(2004). El sur y los trópicos: ensayos de cultura latinoamericana (Cuadernos de América Sin Nombre). Alicante: Universidad de Alicante.

PRAD0, Maria Ligia Coelho (2009). "Identidades latinoamericanas (18701930)". In: Enrique Ayala Mora (director), Eduardo Posada Carbó (Codirector) (Org.); Historia General de América Latina Volumen VII: Los proyectos nacionales latinoamericanos: sus instrumentos y articulación, 1870-1930. Ied. Paris: Ediciones UNESCO/ Editorial Trotta, v. VII, p. 583-615.

RAMA, Ángel

(1984). A cidade das letras. São Paulo: Editora Brasiliense.

SARL0, Beatriz

(1997). "Vanguardia y criollismo: la aventura de Martín Fierro". In: Carlos Altamirano; Beatriz Sarlo (Orgs.); Ensayos argentinos: de 
Sarmiento a la vanguardia. Argentina: Ariel, p.127-171.

(2010). Modernidade Periférica: Buenos Aires 1920 e 1930. São Paulo: Cosac Naify.

SCHWARTZ, Jorge; ALCALÁ, May Lorenzo (1992). Vanguardas argentinas: anos 20. São Paulo: Iluminuras.

SCHWARTZ, Jorge (1993). "Abaixo Tordesilhas!". Estudos Avançados. vol 7, n. 17, p. 185-200.

(1995). Vanguardas Latino-americanas: polêmicas, manifestos e textos críticos. São Paulo: Editora Universidade de São Paulo; Iluminuras; FAPESP.
ZANETTI, Susana

(1994). “Modernidad y religación: uma perspectiva continental (1880-1916)". In: Ana Pizarro (Org.); América Latina: palavra, literatura e cultura. São Paulo: Memorial; Campinas: Unicamp.

\section{Recebido em}

janeiro de 2014

Aprovado em

março de 2014 